\title{
Understanding auditory neuropathy spectrum disorder: a system- atic review in transgenic mouse models
}

\author{
Li Wang ${ }^{1,2}$, Jing Guan ${ }^{1}$, Hongyang Wang ${ }^{1}$, Lan Lan ${ }^{1}$, Qiujing Zhang ${ }^{1}$, Liang Zong ${ }^{1}$, Wan Du ${ }^{1}$, \\ Wenping Xiong ${ }^{1}$, Fengjiao $\mathrm{Li}^{1}$, Kaiwen $\mathrm{Wu}^{1}$, Dayong Wang ${ }^{1}$ \& Qiuju Wang ${ }^{1 *}$ \\ ${ }^{1}$ Institute of Otolaryngology, Chinese PLA General Hospital, Medical School of Chinese PLA, Beijing 100853, China; \\ ${ }^{2}$ Medical College, Nankai University, Tianjin 300071, China
}

Received October 12, 2015; accepted November 3, 2015; published online January 15, 2016

\begin{abstract}
Auditory neuropathy spectrum disorder is a unique group of hearing dysfunctions characterized by preserved outer hair cell function and abnormal neural conduction of the auditory pathway. However, the pathogenic mechanism underlying this disorder is not clear. We therefore performed a systematic review of genetic mouse models with different gene mutations to provide a valuable tool for better understanding of the process and the possible molecular mechanisms. Of the 18 articles retrieved, nine met the required criteria. All biochemical, histological, and electrophysiological results were recorded for each of the mouse models, as was the transgenic technology. This review provides a summary of different mouse models that may play an important role in the diagnosis and management of auditory neuropathy spectrum disorder in the future.
\end{abstract}

auditory neuropathy spectrum disorder, transgenic mouse models, pathogenesis, systematic review

Citation: $\quad$ Wang, L., Guan, J., Wang, H., Lan, L., Zhang, Q., Zong, L., Du, W., Xiong, W., Li, F., Wu, K., Wang, D., and Wang, Q. (2016). Understanding auditory neuropathy spectrum disorder: a systematic review in transgenic mouse models. Sci China Life Sci 59, 480-486. doi: $10.1007 / \mathrm{s} 11427-015-4985-2$

\section{INTRODUCTION}

Auditory neuropathy, also referred to as auditory neuropathy spectrum disorder (ANSD), is a disorder that affects the speech perception ability. It is characterized by abnormal neural conduction in the auditory pathway, with preservation of outer hair cell function. The audiological examination indicates absent or abnormal auditory brainstem responses (ABR), and the presence of otoacoustic emissions (OAE) and/or cochlear microphonics (CM) (Matsunaga et al., 2012; Norrix and Velenovsky, 2014; Starr et al., 1996). This is reportedly separate from sensorineural hearing loss, as patients who suffer from ANSD also tend to have difficulty with speech perception, which is not in balance with their hearing level. This is suggested by the dyssynchronous neural response, also referred to as auditory dyssynchrony

*Corresponding author (email: wqcr301@sina.com)
(AD) (Vlastarakos et al., 2008). ANSD may originate within the auditory nerve (postsynaptic), or the inner hair cells (IHCs) and their synapses with auditory nerve terminals (presynaptic) (Rance, 2005; Starr et al., 2000), and in certain situations may result from a combination of any of the locations. Because of this, it has been named "auditory neuropathy spectrum disorder" (Manchaiah et al., 2011), a confusing terminology. ANSD can appear as an isolated nonsyndromic disorder, or as a component of a syndrome, such as a group of motor and/or sensory neuropathies like Friedrich's ataxia. Both acquired and congenital forms of ANSD could be caused by a genetic disorder or a number of other etiologies, such as an infection, toxic metabolic damage, or even hypercholesterolemia (Vlastarakos et al., 2008). However, the etiologic factors have not been identified in roughly $50 \%$ of patients (Santarelli, 2010). Thus, it is important to learn more about the pathogenic mechanisms to have a greater understanding of ANSD. 
Genetic testing is rapidly evolving worldwide, and an increasing number of genes have been found to be associated with ANSD. Mutations of DIAPH3 (AUNA1), OTOF, AlFM1 (AUNX1), PJVK, and even mitochondrial 12S rRNA have been identified. These have all been shown to be causal in isolated ANSD. On the other hand, mutations such as PMP22, OPAl, NF-L, MPZ, GJB1, and TMEM$126 A$ have been shown to be causal in syndromic ANSD (Zhang and Wang, 2014; Zong et al., 2015). Identical ANSD genes in animal models enable exploration of gene function and the pathogenesis of this disorder.

Meanwhile, there is significant similarity between the mouse and human inner ear structures, making the mouse an appropriate animal model (Moser et al., 2013; Pennacchio, 2003). To date, several mouse strains have been inbred to demonstrate hearing ability and the onset of hearing loss (Jones et al., 2006; Zheng et al., 1999); an example is the C57BL/6J (B6) strain, a popular mouse model of agerelated hearing loss. Studies often use this strain for research on sensorineural hearing loss in progressive aging. Critical hearing loss can be observed at just nine to twelve months of age.

In addition, the organ of Corti has three rows of outer hair cells (OHCs) and just one row of IHCs. The apical surfaces of both of these are sensitive and have several dozen stereocilia. Moreover, the mouse models enable ultrastructural and histopathological research, and electrophysiological measurements can be studied (Kikkawa et al., 2012). Because of this, the fine line that separates mouse and human genetics can be of use in the study of genes that are already known to cause deafness. We reviewed the genetic mouse models of ANSD, a research field that has experienced remarkable advances in the last few years.

\section{RESULTS}

\section{Description of the transgenic mouse models in the studies}

A total of 18 articles were found in the search; however, after comparing the criteria, only nine were used in the systematic review. Figure 1 shows the flow diagram.

Table 1 reviews the characteristics that were identified in the studies, according to the publication time. Eight of the nine studies examined various deafness genes and their functions using transgenic animal models. The remaining study (May et al., 2011) examined the relationship between noise-induced auditory neuropathy and the medial olivocochlear system, instead of a specific ANSD gene. In addition, studies on many different mouse strains were identified, including one on the C57 mouse, another on the $129 / \mathrm{Sv}$ mouse, and one each on BALB/c and FVB/NJ mouse strains. In addition, two studies mixed 129 and C57 strains, one combined 129/Sv with FVBn, one mixed CBA and 129 , and one used an unknown strain.

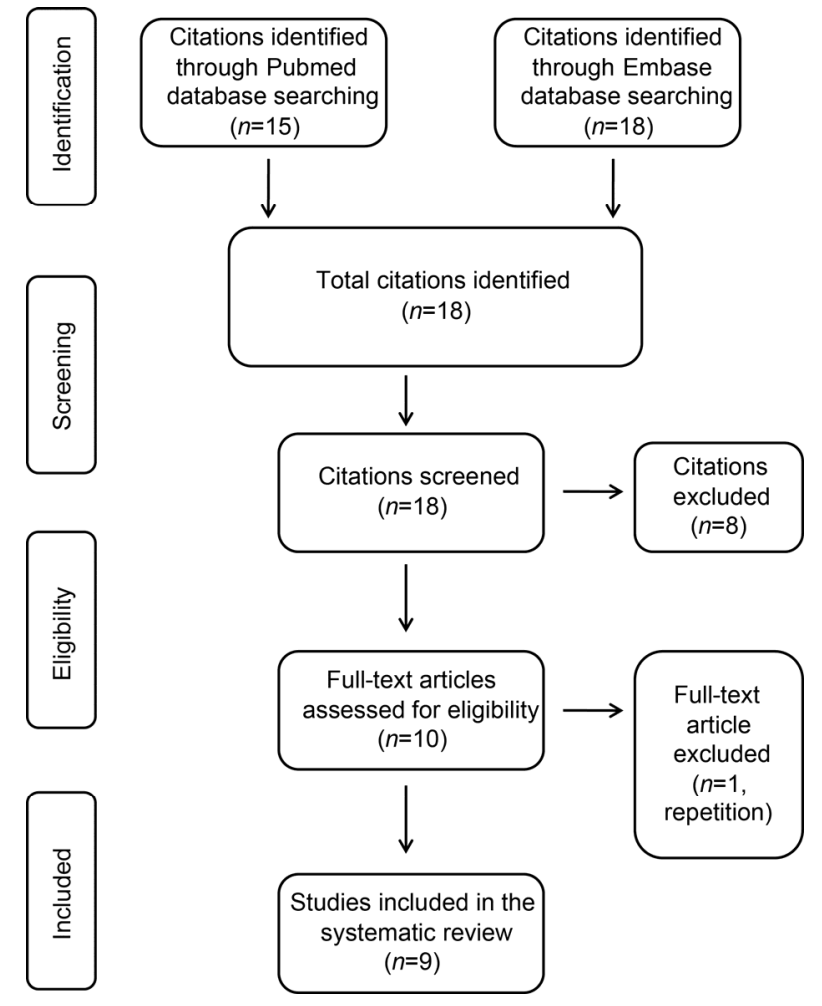

Figure 1 Flow chart of the systematic review.

For the majority of studies, transgenic technologies gave way to knockout mouse models and led to further study with the phenotype; only one of the studies used a knock-in mouse (Delmaghani et al., 2006), in which DNA was injected into fertilized eggs in order to create transgenic mice. The knockout mice had been created by inserting a targeted and modified non-working gene into embryonic stem cells of the mouse. Selections of clones were then integrated into the genome by homologous recombination. This allowed the takeover of wild type alleles. The embryonic stem cells were then usable for generating chimeric mice; over time, the mice began to host the allele that was targeted within the germline. This was done within a homozygous or heterozygous state (Thomas and Capecchi, 1987). The use of the Cre/loxP recombinase system was the best method for generating knockouts. Using the gene targeting approach described above, knock-in mice that were different from knockout mice could be generated by introducing a certain variant into the targeting vector.

\section{Risk of bias and study quality}

Figure 2 shows the results of the risk of bias assessment of the nine different studies in the systematic review. Considered the unique characteristics of the processes by which transgenic mice had been created, the random selection of experimental animals and observed indicators could not be completed. Therefore, the study quality was assessed using five items, including animal welfare. Figure 2 shows that 
Table 1 Details of transgenic mice in the every study ${ }^{a)}$

\begin{tabular}{|c|c|c|c|c|c|}
\hline NO. & Gene & Mouse strain & Types & Technology & Time \\
\hline 1 & $C \times 29$ & $\mathrm{BALB} / \mathrm{c}$ & $\mathrm{KO}^{*}$ & $\begin{array}{l}\text { Western blotting, immunofluorescent labeling, } \\
\text { electron-microscopic scan }\end{array}$ & $\begin{array}{l}\text { 2006.2 (Tang et al., } \\
2006 \text { ) }\end{array}$ \\
\hline 2 & Slc19a2 & $129 \mathrm{~S} 4 / \mathrm{SvJae}$ & $\mathrm{KO}$ & 3D neurolucida software, cytocochleogram & $\begin{array}{l}\text { 2006.3 (Liberman et al., } \\
\text { 2006) }\end{array}$ \\
\hline 3 & Pjvk & mixed C57BL/6-129/Sv & $\mathrm{KI}^{*}$ & $\begin{array}{l}\text { Morphology, immunofluorescence analyses, } \\
\text { immunocytofluorescence }\end{array}$ & $\begin{array}{l}2006.7 \text { (Delmaghani et al., } \\
\text { 2006) }\end{array}$ \\
\hline 4 & Otof & mixed C57BL/6-129/SvPas & $\mathrm{KO}$ & $\begin{array}{l}\text { Immunohistofluorescence, Electron microscopy, } \\
\text { Immunoblotting and immunoprecipitation, }\end{array}$ & $\begin{array}{l}2006.10 \text { (Roux et al., } \\
2006 \text { ) }\end{array}$ \\
\hline 5 & Slitrk6 & C57BL/6J & $\mathrm{KO}$ & $\begin{array}{l}\text { In situ hybridization, immunohistochemistry, Southern } \\
\text { blot, RT-PCR,RT-PCR }\end{array}$ & $\begin{array}{l}2009 \text { (Katayama et al., } \\
\text { 2009) }\end{array}$ \\
\hline 6 & $n A C h \alpha 9$ & mixed $129 / \mathrm{Sv}-\mathrm{CBA} / \mathrm{CaJ}$ & $\mathrm{KO}$ & Electrophysiological methods & 2011.12 (May et al., 2011) \\
\hline 7 & Cx32 & unknown & $\mathrm{KO}$ & $\begin{array}{l}\text { Western Blot, immunofluorescent staining, } \\
\text { epifluorescent microscopy }\end{array}$ & 2011.09 (B.D. et al., 2011) \\
\hline 8 & Diaph3 & $\mathrm{FVB} / \mathrm{NJ}$ & $\begin{array}{l}\text { Transgenesis for } \\
\text { diap3-overpressing }\end{array}$ & $\begin{array}{l}\text { SEM, immunohistochemistry, quantitative reverse } \\
\text { transcription PCR (qRT-PCR) }\end{array}$ & $\begin{array}{l}\text { 2013.2 (Schoen et al., } \\
\text { 2013) }\end{array}$ \\
\hline 9 & Foxo3 & mixed FVBn-129Sv & $\mathrm{KO}$ & $\begin{array}{l}\text { 3D modeling, quantitative PCR, Western analysis, and } \\
\text { immunofluorescence, histological techniques }\end{array}$ & $\begin{array}{l}\text { 2013.10 (Gilels et al., } \\
\text { 2013) }\end{array}$ \\
\hline
\end{tabular}

a) $\mathrm{KO}^{*}$, knock-out mice; $\mathrm{KI}^{*}$, knock-in mice.

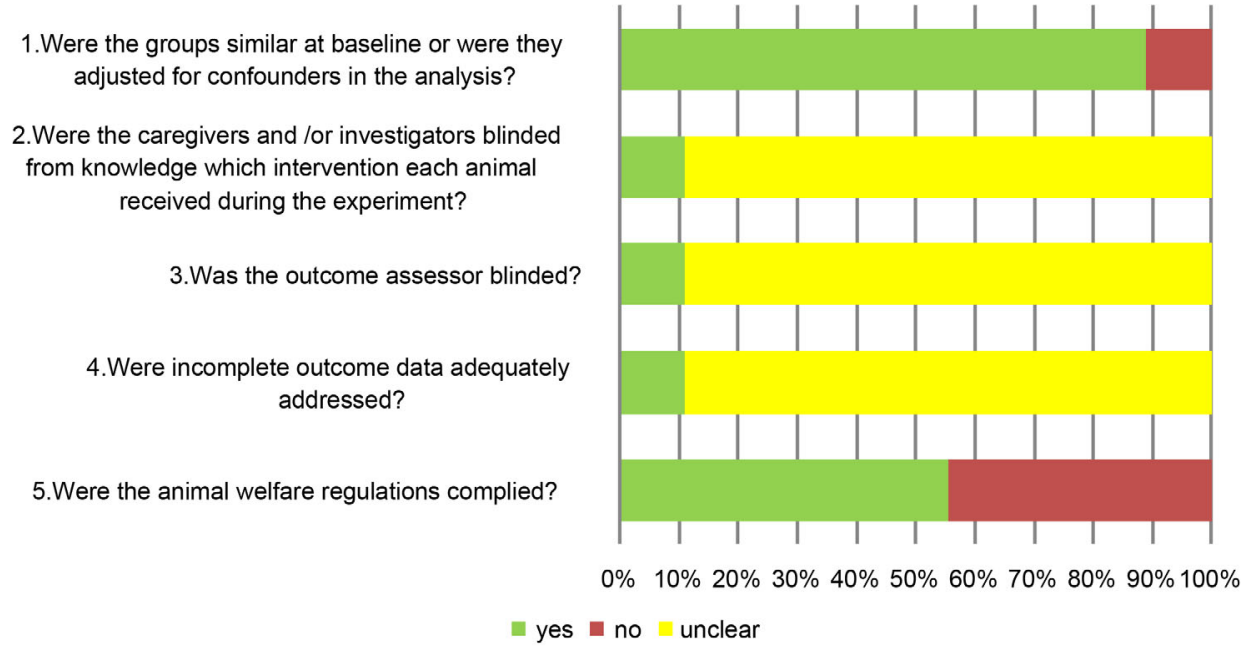

Figure 2 Risk of bias, score (\%) per risk of bias item.

$88.89 \%$ of the research produced a similar baseline, which can be explained by the background of the mice or the conditions of the control group. However, most of the nine studies did not provide a randomized method. A majority also failed to state whether the allocation had been concealed adequately, showing room for improved research.

\section{Audiological evaluations and inner ear morphology}

Even though each mouse had been studied for a different gene, nearly all had hearing loss. The overall design of the organ of Corti was monitored in many of the studies in order to gain a deeper understanding of the cause of ANSD. No abnormal morphology within the organ of Corti was recorded; however, the spiral ganglion neurons (SGN) and hair cells often showed abnormalities. The functions of $\mathrm{OHC}$ could be reviewed with the measurement of distortion product otoacoustic emissions/otoacoustic emissions (DPOAE/OAE); with ABR, the auditory neuropathy and
IHC could also be assessed. The differences between the auditory functional structures varied based on the different gene mutations used, and nearly all the ABR's largely varied between experimental mice and control groups, as shown in Table 2.

\section{Experiment methods and possible pathogenesis}

Table 1 shows that molecular biological techniques, immunohistochemistry, and scanning electron microscopy (SEM) were commonly used for experimentation on mice. These techniques helped reveal the possible pathogenesis underlying ANSD, as analyzed in Table 2. This enabled us to conclude that ANSD pathogenesis can originate in any location, ranging from auditory neurons to IHCs.

\section{DISCUSSION}

Within the past 10 years, many genes associated with the 
Table 2 Studies of morphology, audiological evaluations and the pathogenesis ${ }^{\text {a) }}$

\begin{tabular}{|c|c|c|c|c|c|c|c|}
\hline \multirow{2}{*}{ NO. } & \multicolumn{4}{|c|}{ Morphology } & \multicolumn{2}{|c|}{ Audiometry } & \multirow{2}{*}{ Pathogenesis of ANSD } \\
\hline & Corti & SGN & IHC & $\mathrm{OHC}$ & $\mathrm{ABR}$ & DPOAE/OAE & \\
\hline 1 & $\mathrm{~N}$ & demyelin & $\mathrm{N}$ & $\mathrm{N}$ & A & $\mathrm{N}$ & Severe demyelination at SGN soma \\
\hline 2 & $\mathrm{~N}$ & $\mathrm{~N}$ & loss & $\begin{array}{l}\text { loss after } \\
\text { IHC }\end{array}$ & $\begin{array}{l}\text { large threshold } \\
\text { shift }^{\#}\end{array}$ & $\begin{array}{l}\text { small threshold } \\
\text { shift }^{\#}\end{array}$ & IHC absence \\
\hline 3 & $\mathrm{~N}$ & $\mathrm{~N}$ & $\mathrm{~N}$ & $\mathrm{~N}$ & A & $\mathrm{N}$ & $\begin{array}{l}\text { Neurons dysfunction along auditory path- } \\
\text { way }\end{array}$ \\
\hline 4 & $\mathrm{~N}$ & $\mathrm{~N}$ & $\mathrm{~N}$ & $\mathrm{~N}$ & A & $\mathrm{N}$ & Exocytosis in IHC abolished \\
\hline 5 & $\mathrm{~N}$ & loss & $\mathrm{N}$ & $\mathrm{N}$ & NM & NM & SGN loss \\
\hline 6 & NM & NM & $\mathrm{N}$ & $\mathrm{N}$ & A & $\mathrm{N}$ & $\begin{array}{l}\text { Noise promotes ANSD by altering the func- } \\
\text { tional maturation of the brain's temporal } \\
\text { pathways }\end{array}$ \\
\hline 7 & $\mathrm{~N}$ & $\mathrm{~N}$ & $\mathrm{~N}$ & $\mathrm{~N}$ & A & NM & Cochlear homeostasis dysregulation \\
\hline 8 & $\mathrm{~N}$ & $\mathrm{~N}$ & $\begin{array}{l}\text { abnormal stere- } \\
\text { ocilia ribbon } \\
\text { synapses loss }\end{array}$ & $\mathrm{N}$ & A & $\begin{array}{l}\text { threshold in- } \\
\text { creased(line 771) }\end{array}$ & $\begin{array}{l}\text { Abnormalities stereocilia of IHC and ribbon } \\
\text { synapses loss }\end{array}$ \\
\hline 9 & $\mathrm{~N}$ & $\mathrm{~N}$ & A & $\mathrm{N}$ & A & $\mathrm{N}$ & Synaptic localization altered \\
\hline
\end{tabular}

a) SGN, spiral ganglion neurons; IHC, inner hair cell; OHC, outer hair cell; ABR, auditory brainstem responses; DPOAE/OAE, distortion product otoacoustic emissions/otoacoustic emissions; N, normal; A, abnormality; NM, not mention; \#, low-thiamine diet.

pathogenesis of ANSD have been identified; thus, both postsynaptic and presynaptic ANSD have added to a clearer understanding of the disorder and its diagnosis. The studies covered eight different genes that helped identify the manner in which they were connected to the pathology of auditory neuropathy. These included $C x 32, C x 29, S L C 19 A 2$, DIAPH3, SLITRK6, OTOF, PJVK, and FOXO3. Each of these can be identified as part of the isolated PJVK, $D I A P H 3$, and OTOF genes, as well as the remaining non-isolated genes involved in multisystemic disorders with optic and peripheral neuropathies. One of the studies showed impairments within the medial olivocochlear system, with an increased risk of environmentally introduced AN, rather than focusing on a particular gene.

Table 2 schematically illustrates all possible underlying pathophysiological mechanisms in ANSD among the various mouse models. Based on normal physiological processes in the cochlear, the temporal precision of acoustic signaling can be related to rapid synaptic release and the activation of the postsynaptic membrane, as well as propagation along the auditory nerve fibers (Santarelli, 2010). If any of the presynaptic mechanisms get disrupted, it can cause the precession to be off with the temporal coding. This could also interfere with the reliability of synaptic transmissions, which could lead to ANSD (McMahon et al., 2008). An example of a typical presynaptic disorder that leads to ANSD is abnormal exocytosis in OTOF mutations (Roux et al., 2006). There can also be abnormal functioning in the IHC stereocilia caused by SLC19A2 (Liberman et al., 2006), FOXO3 (Gilels et al., 2013), and DIAPH3 (Schoen et al., 2013) genes. At the same time, auditory nerve fibers and postsynaptic membranes adapt to provide quick and precise signal transmission (Santarelli, 2010). However, the knockout mouse Slitrk6 (Katayama et al., 2009) had 50\% fewer SGN, with a reduced number of axon projections to cochlear hair cells.
The auditory SGN with demyelination represented another possible postsynaptic mechanism. This, however, is expected to reduce the speed of conduction when there is disruption of temporal coding (dyssynchrony) (Santarelli, 2010; Zeng et al., 2005). A reduction of nerve fiber numbers located in the axonal neuropathies resulted in a lower auditory input within the brain stem. It is likely the pathophysiology and demyelinating mechanism of ANSD in the mice lacking $C x 29$ gene (Tang et al., 2006).

Oddly enough, the PJVK transgenic mice did not show any abnormalities (Delmaghani et al., 2006), but one study did strongly suggest that a primary lesion within DNB59 and impaired hearing do not originate within the cochlear. Alternatively, the information suggested that a dysfunction took place within the neurons of the auditory pathway, and this coincided with an observation of the distribution of pejvakin within the bodies of SGN and brainstem auditory nuclei (Delmaghani et al., 2006). Additionally, research from Johns Hopkins (May et al., 2011) showed that noise promotes ANSD by altering maturation in the brain's temporal pathway. This has given rise to analytic findings from mouse models, like those in this study, and should help explain heterogeneity and its causes.

Due to the lack of accurate tests for diagnosing dysfunction and the large range of outcomes, ANSD is often confusing and difficult to diagnose. Audiological function can sometimes be examined by use of physiological tools (Giraudet and Avan, 2012; Korver et al., 2012), which are helpful for CM, OAE, and ABR. The integrity of OHC may be determined by testing OAE. However, audiological tools used to examine the function of the afferent pathway, from the IHC to cranial nerve VIII, cannot identify the exact site of dysfunction (Norrix and Velenovsky, 2014). Thus, it is not possible to completely isolate IHC loss from synaptic dysfunction or neural hearing loss (axonal loss or dyssynchrony due to demyelination) based on physiologic tests. 
The studies used 3-dimensional models created using multiple techniques. One study model provided data on the nucleus, stereocilia, and IHC changes. In particular, the other provided a reconstruction of synaptic sections, which were used to determine the distribution quantity and synaptic numbers.
Research on mice with hereditary hearing loss has helped identify dozens of different genes, along with the encoded proteins that are important for both development and maintenance of normal hearing. ANSD-related gene function in connection with typical electrophysiological patterns was obtained by comparing research with the findings of

Table 3 Search strategy

\begin{tabular}{|c|c|}
\hline Search NO. & Search details \\
\hline 1 & $\begin{array}{l}\text { ("Auditory neuropathy" [Supplementary Concept] OR “Auditory neuropathy" [All Fields] OR "auditory neuropathy" [All Fields]) OR } \\
\text { (("Auditory neuropathy" [Supplementary Concept] OR "Auditory neuropathy" [All Fields] OR "auditory neuropathy" [All Fields]) AND } \\
\text { ("Spectrum" [Journal] OR "spectrum" [All Fields] OR "IEEE Spectr" [Journal] OR "spectrum" [All Fields]) AND (“disease" [MeSH } \\
\text { Terms] OR "disease" [All Fields] OR "disorder" [All Fields])) OR (“Auditory neuropathy" [Supplementary Concept] OR “Auditory neu- } \\
\text { ropathy" [All Fields] OR "auditory dys synchrony" [All Fields]) }\end{array}$ \\
\hline 2 & “mice” [MeSH Terms] OR “mice” [All Fields] OR “mouse” [All Fields] \\
\hline 3 & 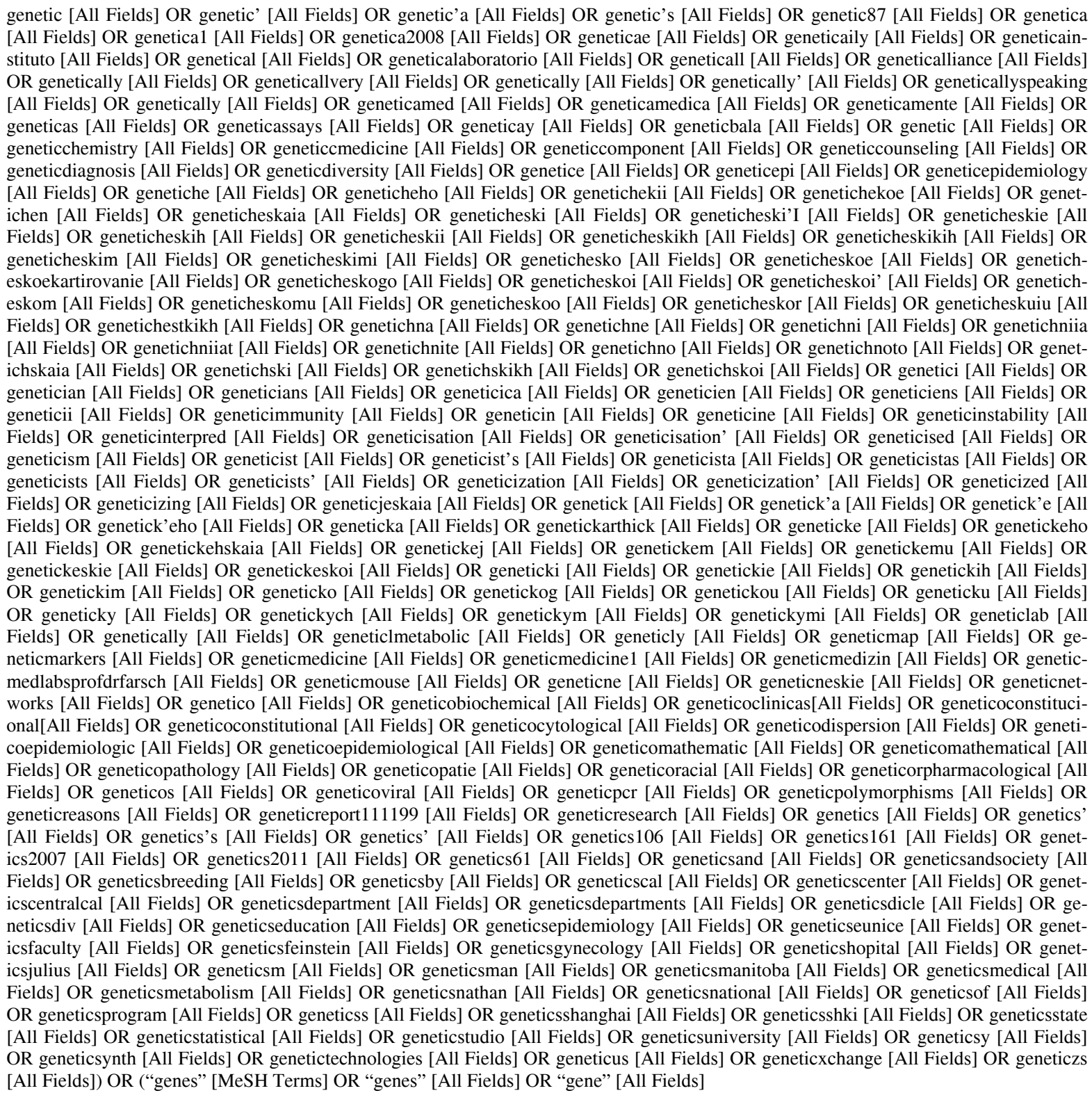 \\
\hline 4 & 1 and 2 and 3 \\
\hline 5 & limits: publication from January 1996 to May 2015, all languages \\
\hline
\end{tabular}


mouse models. This could be a key point in revealing how different molecular processes and their failures underlie ANSD.

This study has several limitations. Systematic reviews are vulnerable to a variety of biases (Hirst et al., 2014). The quality of the transgenic mouse studies on ANSD was poor, because the small number of studies avoided performance, detection, and reporting bias, which highlights the requirement for animal research to reduce the risk of biased results and improve translatability in the future.

\section{METHODS}

\section{Literature search}

The EMBASE and PubMed databases were used for a literature review as they provided articles published between 1996 and 2015. As the first report of auditory neuropathy was in 1996, this was the initial point of the time frame. The plan for research was to locate information using Medical Subject Headings (MeSH) terms and keywords such as "gene," "mouse," and "auditory disease," along with synonyms for each in PubMed, as shown in Table 3. Then, similar terms were searched with EMBASE. In addition, the reference citations were also retrieved in order to further research and locate other articles related to the study. All work was done by just three researchers, working independently.

\section{Study selection}

The inclusion criteria were as follows: (i) original articles; (ii) articles that contained information on mouse model genetics and disorders directly or indirectly related to auditory issues; (iii) connections between ANSD pathogenesis and mouse models; (iv) only recently published information or completed data were used in the study. Discussions were held to identify differences between selections. A relevant article would be selected by one of the researchers, then passed to a second researcher who would check it against an original article. A meta-analysis was not possible because of heterogeneity in the mouse models. Figure 1 shows the flow chart and process of the reviews.

\section{Data extraction}

Information extracted from each of the studies included transgenic technology, animal strain, types of ANSD-related genes, details of outcome measurements (such as biochemical, electrophysiological, and histological outcomes), and even pathogenic mechanisms. These items were recorded for every study.

A 5-item checklist was used to help assess methodological quality related to the animal models, using SYRCLE's risk of bias tool (Hooijmans et al., 2014). The quality checks for all studies were done by three investigators working independently. Any disagreements were discussed and resolved. The biochemical, electrophysiological, and histological outcomes differed greatly; as a result, they could not be placed into categories and were reported separately.

Compliance and ethics The author(s) declare that they have no conflict of interest.

Acknowledgements We are grateful to the professors of the Chinese PLA Institute of Otolaryngology for their support and encouragement. This work was supported by the National Key Basic Research Program of China (2014CB943001), and the National Natural Science Foundation of China (81120108009, 81530032).

Delmaghani, S., del Castillo, F.J., Michel, V., Leibovici, M., Aghaie, A., Ron, U., Van Laer, L., Ben-Tal, N., Van Camp, G., Weil, D., Langa, F., Lathrop, M., Avan, P., and Petit, C. (2006). Mutations in the gene encoding pejvakin, a newly identified protein of the afferent auditory pathway, cause DFNB59 auditory neuropathy. Nat Genet 38, 770-778.

Gibson, B.D., Sollas, A., Mattiace, L.A., Yu, G.P., and Kim, A.H. (2011). Role of Connexin 32 (Cx32) and Hearing Loss In Charcot-Marie-Tooth Syndrome (CMTS) A. Laryngoscope 121(Supplement 5), S321.

Gilels, F., Paquette, S.T., Zhang, J., Rahman, I., and White, P.M. (2013). Mutation of Foxo3 causes adult onset auditory neuropathy and alters cochlear synapse architecture in mice. J Neurosci 33, 18409-18424.

Giraudet, F., and Avan, P. (2012). Auditory neuropathies: understanding their pathogenesis to illuminate intervention strategies. Curr Opin Neurol $25,50-56$

Hirst, J.A., Howick, J., Aronson, J.K., Roberts, N., Perera, R., Koshiaris, C., and Heneghan, C. (2014). The need for randomization in animal trials: an overview of systematic reviews. PLoS One 9, e98856.

Hooijmans, C.R., Rovers, M.M., de Vries, R.B., Leenaars, M., Ritskes-Hoitinga, M., and Langendam, M.W. (2014). SYRCLE's risk of bias tool for animal studies. BMC Med Res Methodol 14, 43.

Jones, S.M., Jones, T.A., Johnson, K.R., Yu, H., Erway, L.C., and Zheng, Q.Y. (2006). A comparison of vestibular and auditory phenotypes in inbred mouse strains. Brain Res 1091, 40-46.

Katayama, K., Zine, A., Ota, M., Matsumoto, Y., Inoue, T., Fritzsch, B., and Aruga, J. (2009). Disorganized innervation and neuronal loss in the inner ear of Slitrk6-deficient mice. PLoS One 4, e7786.

Kikkawa, Y., Seki, Y., Okumura, K., Ohshiba, Y., Miyasaka, Y., Suzuki, S., Ozaki, M., Matsuoka, K., Noguchi, Y., and Yonekawa, H. (2012). Advantages of a mouse model for human hearing impairment. Exp Anim 61, 85-98.

Korver, A.M., van Zanten, G.A., Meuwese-Jongejeugd, A., van Straaten, H.L., and Oudesluys-Murphy, A.M. (2012). Auditory neuropathy in a low-risk population: a review of the literature. Int J Pediatr Otorhinolaryngol 76, 1708-1711.

Liberman, M.C., Tartaglini, E., Fleming, J.C., and Neufeld, E.J. (2006). Deletion of SLC19A2, the high affinity thiamine transporter, causes selective inner hair cell loss and an auditory neuropathy phenotype. J Assoc Res Otolaryngol 7, 211-217.

Manchaiah, V.K., Zhao, F., Danesh, A.A., and Duprey, R. (2011). The genetic basis of auditory neuropathy spectrum disorder (ANSD). Int J Pediatr Otorhinolaryngol 75, 151-158.

Matsunaga, T., Mutai, H., Kunishima, S., Namba, K., Morimoto, N., Shinjo, Y., Arimoto, Y., Kataoka, Y., Shintani, T., Morita, N., Sugiuchi, T., Masuda, S., Nakano, A., Taiji, H., and Kaga, K. (2012). A prevalent founder mutation and genotype-phenotype correlations of OTOF in Japanese patients with auditory neuropathy. Clin Genet 82, 425-432.

May, B.J., Lauer, A.M., and Roos, M.J. (2011). Impairments of the medial olivocochlear system increase the risk of noise-induced auditory neuropathy in laboratory mice. Otol Neurotol 32, 1568-1578.

McMahon, C.M., Patuzzi, R.B., Gibson, W.P., and Sanli, H. (2008). Fre- 
quency-specific electrocochleography indicates that presynaptic and postsynaptic mechanisms of auditory neuropathy exist. Ear Hear 29, 314-325.

Moser, T., Predoehl, F., and Starr, A. (2013). Review of hair cell synapse defects in sensorineural hearing impairment. Otol Neurotol 34, 995-1004.

Norrix, L.W., and Velenovsky, D.S. (2014). Auditory neuropathy spectrum disorder: a review. J Speech Lang Hear Res 57, 1564-1576.

Pennacchio, L.A. (2003). Insights from human/mouse genome comparisons. Mamm Genome 14, 429-436.

Zhang, Q., and Wang, Q. (2014). Review of recent research progress in molecular genetic mechanism of auditory neuropathy spectrum disorder. Zhonghua Er Bi Yan Hou Tou Jing Wai Ke Za Zhi 49, 1040-1045.

Rance, G. (2005). Auditory neuropathy/dys-synchrony and its perceptual consequences. Trends Amplif 9, 1-43.

Roux, I., Safieddine, S., Nouvian, R., Grati, M., Simmler, M.C., Bahloul, A., Perfettini, I., Le Gall, M., Rostaing, P., Hamard, G., Triller, A., Avan, P., Moser, T., and Petit, C. (2006). Otoferlin, defective in a human deafness form, is essential for exocytosis at the auditory ribbon synapse. Cell 127, 277-289.

Santarelli, R. (2010). Information from cochlear potentials and genetic mutations helps localize the lesion site in auditory neuropathy. Genome Med 2, 91.

Schoen, C.J., Burmeister, M., and Lesperance, M.M. (2013). Diaphanous homolog 3 (Diap3) overexpression causes progressive hearing loss and inner hair cell defects in a transgenic mouse model of human deafness. PLoS One 8, e56520.
Starr, A., Picton, T.W., Sininger, Y., Hood, L.J., and Berlin, C.I. (1996). Auditory neuropathy. Brain 119 ( Pt 3), 741-753.

Starr, A., Sininger, Y.S., and Pratt, H. (2000). The varieties of auditory neuropathy. J Basic Clin Physiol Pharmacol 11, 215-230.

Tang, W., Zhang, Y., Chang, Q., Ahmad, S., Dahlke, I., Yi, H., Chen, P., Paul, D.L., and Lin, X. (2006). Connexin29 is highly expressed in cochlear Schwann cells, and it is required for the normal development and function of the auditory nerve of mice. J Neurosci 26, 1991-1999.

Thomas, K.R., and Capecchi, M.R. (1987). Site-directed mutagenesis by gene targeting in mouse embryo-derived stem cells. Cell 51, 503-512.

Vlastarakos, P.V., Nikolopoulos, T.P., Tavoulari, E., Papacharalambous, G., and Korres, S. (2008). Auditory neuropathy: endocochlear lesion or temporal processing impairment? Implications for diagnosis and management. Int J Pediatr Otorhinolaryngol 72, 1135-1150.

Zeng, F.G., Kong, Y.Y., Michalewski, H.J., and Starr, A. (2005). Perceptual consequences of disrupted auditory nerve activity. J Neurophysiol 93, 3050-3063.

Zheng, Q.Y., Johnson, K.R., and Erway, L.C. (1999). Assessment of hearing in 80 inbred strains of mice by ABR threshold analyses. Hear Res 130, 94-107.

Zong, L., Guan, J., Ealy, M., Zhang, Q., Wang, D., Wang, H., Zhao, Y., Shen, Z., Campbell, C.A., Wang, F., Yang, J., Sun, W., Lan, L., Ding, D., Xie, L., Qi, Y., Lou, X., Huang, X., Shi, Q., Chang, S., Xiong, W., Yin, Z., Yu, N., Zhao, H., Wang, J., Wang, J., Salvi, R.J., Petit, C., Smith, R.J., and Wang, Q. (2015). Mutations in apoptosis-inducing factor cause $\mathrm{X}$-linked recessive auditory neuropathy spectrum disorder. J Med Genet 52, 523-531.

Open Access This article is distributed under the terms of the Creative Commons Attribution License which permits any use, distribution, and reproduction in any medium, provided the original author(s) and source are credited. 